\title{
SISTEM PAKAR DIAGNOSA PENYAKIT TANAMAN KAKAO MENGGUNAKAN METODE CERTAINTY FACTOR PADA KELOMPOK TANI PT OLAM INDONESIA (COCOA) CABANG LAMPUNG
}

\author{
Syahirul Alim ${ }^{1)}$, Peni Puji Lestari ${ }^{2)}$, Rusliyawati ${ }^{3)}$ \\ ${ }^{123}$ Program Studi Sistem Informasi, Fakultas Teknik dan Ilmu Komputer, Universitas Teknokrat Indonesia \\ ${ }^{123}$ Jl. Zainal Abidin Pagaralam No. 9-11 Kedaton, Bandar Lampung \\ Email:1'syahirul_alim@teknokrat.ac.id, 2penilestari1808@gmail.com, ${ }^{3}$ rusliyawati@teknokrat.ac.id
}

\begin{abstract}
PT OLAM INDONESIA (Cocoa) Lampung Branch has 2700 fostered farmers. There are various types of diseases that attack cocoa plants. Types of diseases that often attack cacao plants are fruit rot, stem cancer, anthracnose disease, fungal disease, root fungus disease, wood vessel disease (Vascular Steak Dieback). The problem is due to the large number of farmers trained by Olam who do not know the types of diseases and solutions. Based on these problems, the researcher will design an expert system for diagnosing cacao plant diseases using the certainty factor method in the Lampung branch of the Indonesian farmers group (Cocoa). The system built is a system that can diagnose cocoa plant diseases and provide appropriate solutions to diseases that often make cocoa farmers difficult. The final result obtained is the information system of cocoa plant disease diagnosis using certainty factor method which has the ability to determine the type of disease in accordance with the complaints of farmers. This application was tested using an accuracy calculation where the results obtained an accuracy rate of $85.7 \%$ for diagnosis of cocoa plant diseases.
\end{abstract}

Keyword: Expert System, Certainty Factor, Diagnosis of Cocoa Plant Diseases

\begin{abstract}
Abstrak
PT OLAM INDONESIA (Cocoa) Cabang Lampung memiliki petani binaan sebanyak 2700. Ada beragam jenis penyakit yang menyerang tanaman kakao. Jenis penyakit yang sering menyerang tanaman kakao yaitu penyakit busuk buah, penyakit kanker batang, penyakit antraknosa, penyakit jamur upas, penyakit jamur akar, penyakit pembuluh kayu (Vascular Steak Dieback). Permasalahannya adalah dikarenakan banyaknya petani binaan olam yang tidak mengetahui jenis penyakit dan solusi. Berdasarkan masalah tersebut, maka peneliti akan merancang sebuah sistem pakar diagnosa penyakit tanaman kakao menggunakan metode Certainty Factor pada kelompok tani PT Olam Indonesia (Cocoa) cabang Lampung. Sistem yang dibangun adalah sistem yang dapat mendiagnosa penyakit tanaman kakao serta memberikan solusi yang tepat terhadap penyakit yang sering menyusahkan para petani kakao. Hasil akhir yang diperoleh adalah sistem informasi diagnosa penyakit tanaman kakao menggunakan metode Certainty Factor yang memiliki kemampuan untuk mengetahui jenis penyakit sesuai dengan yang dikeluhan petani. Aplikasi ini diuji menggunakan perhitungan akurasi dimana hasilnya didapatkan tingkat akurasi sebesar $85,7 \%$ untuk diagnose penyakit tanaman kakao.
\end{abstract}

Kata Kunci: Sistem Pakar, Certainty Factor, Diagnosa Penyakit Tanaman Kakao

\section{Pendahuluan}

\subsection{Latar Belakang}

Sistem pakar merupakan suatu program komputer yang menggunakan ilmu, fakta, dan teknik berpikir untuk pengambilan keputusan sebagai dasar menyelesaikan masalah-masalah yang biasanya hanya dapat diselesaikan oleh tenaga ahli dalam bidang yang bersangkutan[1]. Sistem pakar merupakan sistem yang berusaha mengadopsi pengetahuan manusia ke dalam komputer agar komputer dapat menyelesaikan masalah seperti yang biasa dilakukan oleh para pakar[2]. Sedangkan menurut [3] sistem pakar adalah salah satu cabang kecerdasan buatan yang menggunakan pengetahuan-pengetahuan khusus yang dimiliki oleh seorang ahli untuk menyelesaikan masalah tertentu.

Sistem pakar yang baik dirancang agar dapat menjadi alat bantu untuk menyelesaikan suatu masalah 
dengan meniru kerja dari para ahli. Bentuk umum sistem pakar adalah suatu program yang dibuat berdasarkan suatu aturan yang menganalisis informasi mengenai suatu masalah yang spesifik serta analisis matematis dari masalah tersebut. Sistem ini memanfaatkan kapabilitasi penalaran untuk mencapai suatu kesimpulan. Sistem pakar tersebut akan diterapkan untuk menyelesaikan masalah berupa diagnosa penyakit pada tanaman kakao. Terdapat banyak metode untuk mendiagnosa penyakit salah satunya adalah Certainty Factor. Penelitian yang dilakukan [4] menyatakan bahwa penerapan metode Certainty Factor untuk mendiagnosa penyakit syaraf tulang belakang dengan menggunakan pengujian akurasi kesesuaian dari data testing yang didapatkan oleh pakar dibandingkan dengan hasil output melalui percobaan sebanyak 50 kali didapatkan hasil output yang sesuai sebanyak 45 atau sebesar 90\%. Menurut [5] penerapan Certainty Factor untuk mendeteksi penyakit tanaman karet menunjukan akurasi hasil diagnosa sistem pakar sebesar $100 \%$. Berdasarkan penelitian [6] didapatkan bahwa tingkat kepercayaan sistem terhadap penyakit kulit pada kucing sebesar 94,5\%, sedangkan penelitian yang dilakukan oleh [7] menggunakan metode Forward Chaining untuk mendiagnosa penyakit lambung didapatkan akurasi sebesar $75 \%$.

Kakao adalah salah satu komoditas ekspor non migas produk utama biji kakao diolah menjadi berbagai produk khususnya minuman makanan, limbah kakao juga dapat dimanfaatkan sebagai pupuk organik. Soesanto Kakao memiliki permintaan produksi baik dalam negeri maupun luar negeri, permintaan ini semakin kuat dengan adanya perkembangan sektor agroindustri [8]. Selain itu, kakao juga banyak diminati berbagai perusahaan pengolah produk coklat dalam meningkatkan produk yang diolahnya sehingga dapat bersaing di dunia bisnis.

PT OLAM INDONESIA (Cocoa) Cabang Lampung adalah perusahaan di bidang ekspor impor biji kakao, salah satu kiat sukses bertanam kakao adalah keberhasilan dalam pengendalian penyakit PT OLAM INDONESIA (Cocoa) Cabang Lampung memiliki petani binaan sebanyak 2700. Salah satu petani binaan adalah Desa Wiyono yang merupakan desa mayoritas penghasilan masyarakatnya dengan cara berkebun, salah satu hasil perkebunanya adalah kakao. Ada beragam jenis penyakit yang menyerang kakao. Jenis penyakit yang sering menyerang kakao yaitu penyakit busuk buah, penyakit kanker batang, penyakit antraknosa, penyakit jamur upas, penyakit jamur akar, penyakit pembuluh kayu (Vascular Steak Dieback).

Dikarenakan banyaknya petani binaan olam yang tidak mengetahui jenis penyakit dan solusi yang harus mereka lalukan, petani harus bertanya kepada pihak sustainability dan pihak sustainability bertanya kepada pakar, sedangkan petani harus dengan cepat dan akurat dalam mengatasi serangan penyakit, apabila petani tidak cepat dan akurat dalam mengetahui solusi penyakit pada tanaman kakao, maka tanaman kakao akan cepat menyebar, dan akan menurunkan kualitas kakao yang menyebabkan kerugian bagi petani dan turunnya penghasilan pada PT OLAM INDONESIA (Cocoa) Cabang Lampung.

Penelitian pada kelompok tani PT OLAM INDONESIA (Cocoa) Cabang Lampung menggunakan metode certainty factor dalam mengidentifikasi penyakit tanaman kakao sesuai dengan pakarnya, karena metode tersebut memiliki kelebihan untuk mengatasi ketidak pastian dalam pengambilan keputusan dengan cara didapatkan dari perhitungan berdasarkan bobot keyakinan seorang pakar dan bobot gejala yang dipilih pengguna yang proses hasil diagnosa dilengkapi gambar sehingga dapat memudahkan pengguna dalam memahami penyakit tanaman kakao.

\section{Landasan Teori}

\subsection{Pakar}

Pakar adalah orang yang memiliki pengetahuan, penilaian, pengalaman, dan metode khusus serta kemampuan untuk menerapkan bakat dan memberikan nasihat serta memecahkan persoalan[9]. Pakar mengetahui fakta mana yang penting dan memahami arti hubungan diantaranya. Sejauh ini tidak ada definisi standar untuk pakar, tetapi performa keputusan dan tingkat pengetahuan orang adalah kriteria umum dalam menentukan apakah seseorang adalah pakar.

\subsection{Sistem Pakar}

Sistem pakar adalah program komputer yang mensimulasi penilaian dan perilaku manusia atau organisasi yang memiliki pengetahuan dan pengalaman ahli dalam bidang tertentu[10]. Biasanya sistem seperti ini berbasis pengetahuan yang berisi akumulasi pengalaman dan satu set aturan untuk menerapkan pengetahuan dasar untuk setiap situasi tertentu. Sistem pakar yang canggih dapat ditingkatkan dengan menambah basis pengetahuan atau set aturan. Pemrosesan yang dilakukan oleh sistem pakar merupakan pemrosesan pengetahuan bukan pemrosesan data pada sistem pakar komputer konvensional. Pengetahuan (knowledge) adalah pemahaman secara praktis maupun teoritis terhadap suatu obyek atau domain tertentu.

Pengetahuan yang digunakan dalam sistem pakar merupakan serangkaian informasi mengenai gejaladiagnosa, sebab-akibat, aksireaksi tentang ustau domain tertentu (misalnya, domain diagnosa medis). Secara umum, definisi tradisional sebuah program komputer biasa: Algoritma + Struktur data $=$ PROGRAM Dalam sistem pakar, definisi berubah menjadi. Mesin inferensi + Pengetahuan $=$ Sistem Pakar

Dengan sistem pakar, masalah yang seharusnya hanya dapat diselesaikan oleh pakar/ahli, dapat diselesaikan oleh orang biasa/awam. Sedangkan para ahli, sistem pakar membantu aktifitas mereka sebagai 
asisten yang seolah-olah sudah mempunyai banyak pengalaman.

\subsection{Certainty Factor}

Certainty Factor merupakan bagian dari certainty theory, yang pertama kali dikenalkan oleh E. H. Shorliffe dan B. G. Buchanan dalam pembuatan MYCIN (adalah aplikasi sistem pakar awal yang dirancang untuk mengidentifikasi infeksi di dalam darah) mencatat bahwa pakar sering kali menganalisis informasi yang ada dengan ungkapan seperti, misalnya: mungkin, kemungkinan besar, dan hampir pasti. Hal ini membuat tim MYCIN menggunakan Certainty Factor guna menggambarkan tingkat kepercayaan pakar terhadap masalah yang dihadapi [11].

\subsection{Metode Pengembangan Sistem}

Adapun metodologi yang digunakan dalam penelitian ini yaitu model Waterfall. Model waterfall [12] adalah model klasik yang bersifat sistematis, dipandang sistematis berurutan terus mengalir kebawah (seperti air terjun) melewati fase-fase perencanaan, pemodelan, implementasi dan pengujian dalam membangun aplikasi. Awal mulai model ini "Linear Sequential Model", seiring waktu sering disebut dengan "classic life cycle" atau metode waterfall. Model yang termasuk dalam generic pada rekayasa perangkat lunak diperkenalkan pertama kali oleh Winston Royce sekitar tahun 1970. Model ini merupakan yang paling banyak dipakai dalam Software Engineering (SE). Disebut dengan waterfall karena tahap demi tahap yang dilalui harus menunggu selesainya tahap sebelumnya dan berjalan berurutan Fase-fase dalam Waterfall Model:

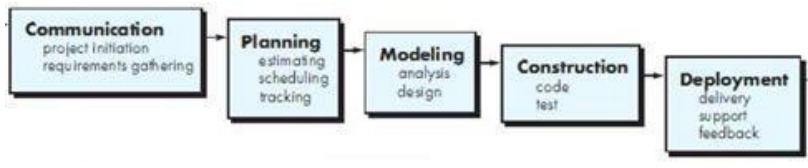

Gambar 1. Waterfall

\subsection{Unified Modeling Language (UML)}

Menurut [13] "UML (Unified Modeling Language) adalah salah satu standar bahasa yang banyak digunakan di dunia industri untuk medefinisikan requirement, membuat analisis dan desain, serta menggambarkan arsitektur dalam pemograman berorientasi objek".

\subsection{Pengujian Black Box}

Teknik yang paling banyak dipakai untuk mengidentifikasi test cases. Dasar utama pemikirannya adalah melakukan analisa terhadap fungsi-fungsi yang terdapat pada suatu sistem, apakah fungsi-fungsi tersebut mempunyai kinerja sebagaimana yang diharapkan atau dispesifikasikan [14].

\subsection{Tanaman Kakao}

Menurut [1] Tanaman kakao berasal Dari Amerika Tengah. Masyarakat suku Maya dan Aztek yang pertama-tama mengusahakan tanaman kakao dan mengestrak bijinya menjadi minumn yang sangat berharga, yang kemudian disebut chocolatl. Istilah ini menjadi awal ke kata Bahasa Inggris modern, yaitu chocolate, yang dalam Bahasa Indonesia menjadi cokelat. Kata Theobroma mempunyai arti sumber makanan dewa, dari kata theo (dewa) dan broma (makanan) ilmuan spanyol, hernan cortez, memperkenalkan minuman cokelat Kekerajaan Spayol. Namun minuman yang pahit itu tidak juga menjadi terkenal selama sekitar 100 tahun. Baru setelah ditambah gula, kayu manis, dan cabai rawit, minuman itu semakin terkenal. Cokelat diperkenalkan ke Eropa jauh sebelum ada kopi dan teh..

\section{Metode Penelitian}

\subsection{Kerangka Penelitian}

Kerangka penelitian merupakan bentuk dari keseluruhan proses dalam sebuah penelitian. Kerangka penelitian dalam penelitian ini dapat dilihat pada gambar berikut.

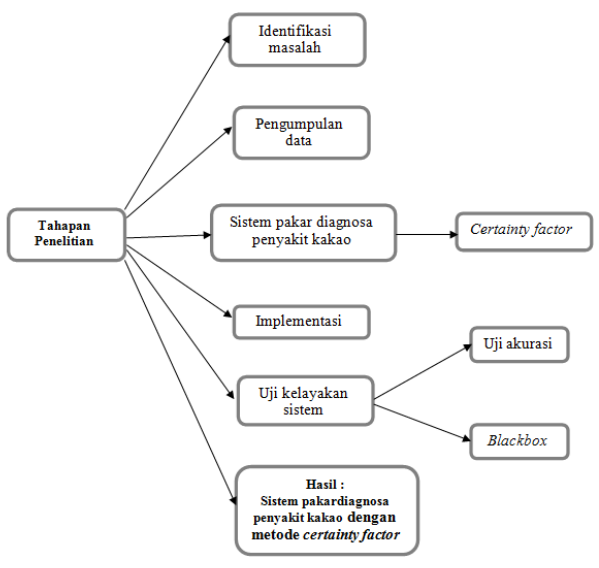

Gambar 2. Kerangka Penelitian

\subsection{Tahapan Penelitian}

Penelitian merupakan kegiatan yang dilakukan secara terencana, teratur, dan sistematis untuk mencapai tujuan tertentu. Tahapan penelitian ini juga merupakan pengembangan dari kerangka penelitian, yang terbagi menjadi beberapa sub menu bagian. Tahapan penelitian yang dilakukan dapat dilihat pada gambar berikut. 


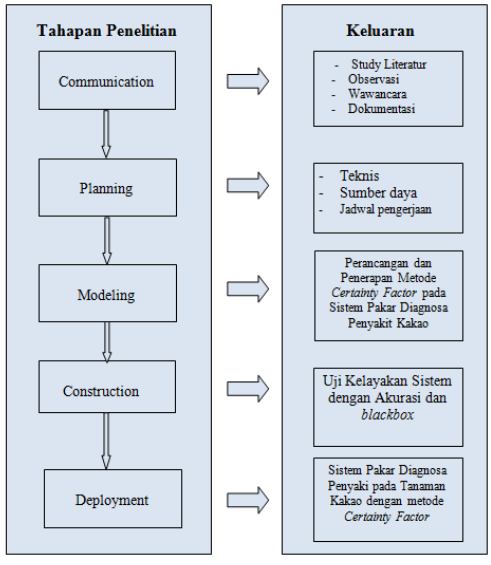

Gambar 3. Tahapan Penelitian

\subsection{Use Case Diagram}

Use case diagram mendeskripsikan sebuah interaksi antara satu atau lebih aktor dengan sistem informasi yang akan dibuat. Gambaran usecase yang digunakan pada penelitian ini dapat dilihat pada gambar berikut.

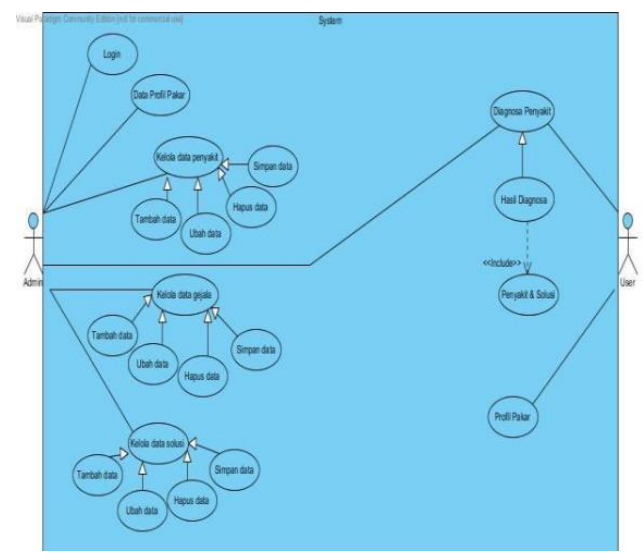

Gambar 4. Use Case Diagram

\subsection{Implementasi}

Implementasi dilakukan untuk menerapkan metode Certainty Factor dan mengidentifikasi penyakit pada tanaman kakao berbasis web dengan bahasa pemograman PHP.

\subsection{Perancangan Pengujian}

Perencanaan pengujian sistem ini menggunakan 2 tahapan pengujian yaitu:

1. Uji Akurasi. Uji akurasi dilakukan untuk mengetahui tingkat akurasi dari sistem pakar yang dibangun. Uji akurasi dilakukan dengan cara mencocokan dari beberapa kasus yang dicocokan dari seorang pakar. Tingkat akurasi dihitung dengan menggunakan rumus.

$$
\text { Akurasi }=\frac{\text { Hasil Tepat }}{\text { Seluruh Data }} \times 100 \%
$$

2. BlackBox Testing. BlackBox digunakan untuk pengujian terhadap fungsional sistem. Pengujian akan dilakukan dengan cara menguji fungsi-fungsi yang ada di dalam sistem yang dibangun. Fungsi-fungsi yang akan diuji dapat dilihat pada tabel berikut.

Tabel 1. Pengujian Blackbox

\begin{tabular}{|l|l|}
\hline \multicolumn{1}{|c|}{ Data Masuk } & \multicolumn{1}{c|}{ Data diharapkan } \\
\hline $\begin{array}{l}\text { Pilih alamat } \\
\text { website sistem } \\
\text { pakar }\end{array}$ & $\begin{array}{l}\text { Dapat menampilkan halaman } \\
\text { website sistem pakar diagnosa } \\
\text { penyakit tanaman kakao }\end{array}$ \\
\hline & $\begin{array}{l}\text { Dapat menampilkan seluruh } \\
\text { gejala,setelah gejala dipilih akan } \\
\text { memberi pilihan berupa } \\
\text { keyakinan user terhadap gejala } \\
\text { yang dipilih dan dapat } \\
\text { menampilkan hasil dan solusi } \\
\text { diagnosa } \\
\text { dari gejala yang telah dipilih }\end{array}$ \\
\hline $\begin{array}{l}\text { Pilih menu profil } \\
\text { pakar }\end{array}$ & $\begin{array}{l}\text { Dapat menampilkan data } \\
\text { informasi tentang pakar }\end{array}$ \\
\hline
\end{tabular}

\section{Hasil dan Pembahasan}

\subsection{Tampilan Sistem Pakar Diagnosa Penyakit Tanaman Kakao}

Dibawah ini terdapat tampilan-tampilan dari sistem pakar untuk mendiagnosis penyakit tanaman kakao menggunakan Certainty Factor.

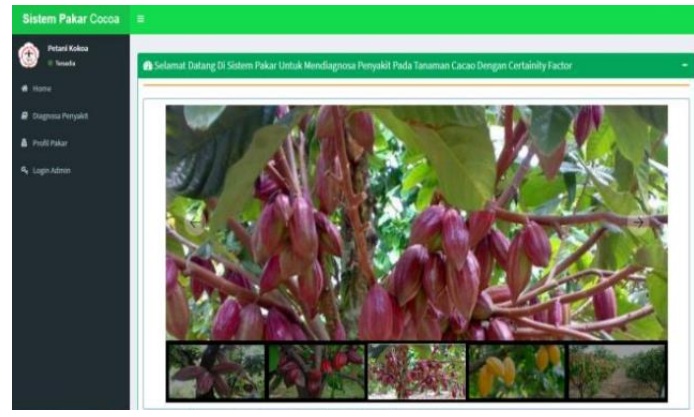

Gambar 5. Menu Utama User

Tampilan menu utama user merupakan tampilan home atau tampilan awal user pada sistem pakar diagnosa penyakit tanaman kakao. Pada tampilan menu utama user juga terdapat menu pilihan halaman diagnosa penyakit, profil pakar dan login admin.

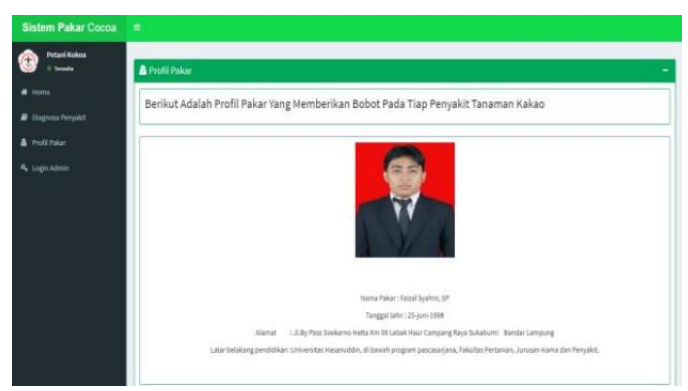

Gambar 6. Tampilan Menu Profil Pakar 
Tampilan menu profil pakar merupakan informasiinformasi tentang pakar yang digunakan untuk memperoleh informasi penyakit dan gejala tanaman kakao.

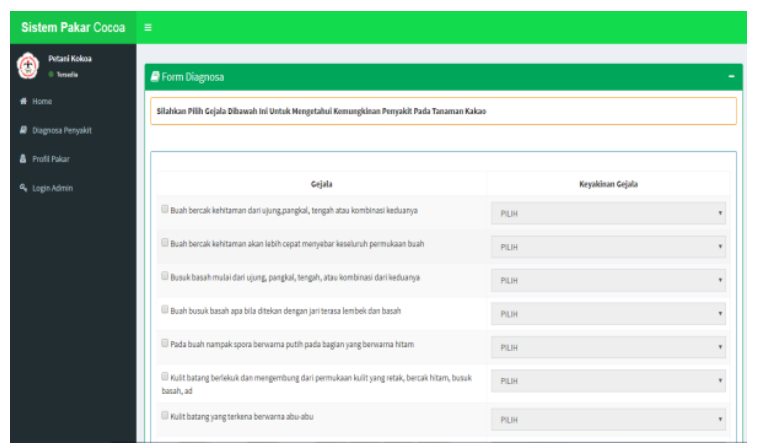

Gambar 7. Tampilan Halaman Menu Diagnosa

Tampilan menu halaman diagnosa dimana user akan melakukan diagnosa penyakit tanaman kakao dengan cara memilih gejala apa saja yang dialami tanaman kakao.

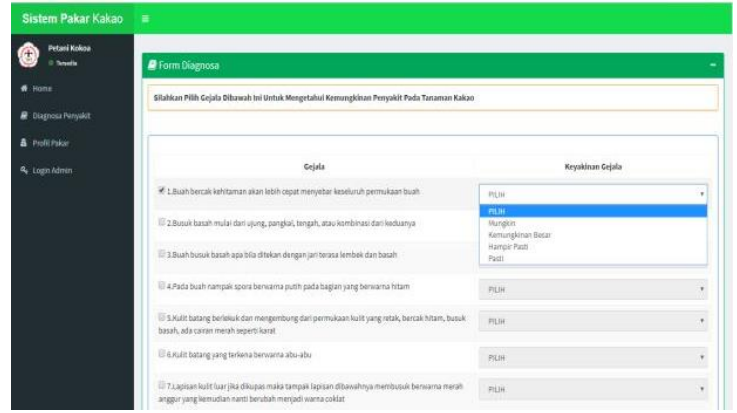

Gambar 8. Tampilan Menu Keyakinan User

Tampilan menu keyakinan user merupakan tampilan pertanyaan-pertanyaan dari setiap gejala yang terjadi pada tanaman kakao. Pada tampilan ini user diwajibkan mengisi setiap pertanyaan dan memilih salah satu keyakinan. Terdapat 4 pilihan keyakinan yaitu mungkin, kemungkinan besar, hampir pasti, dan pasti.

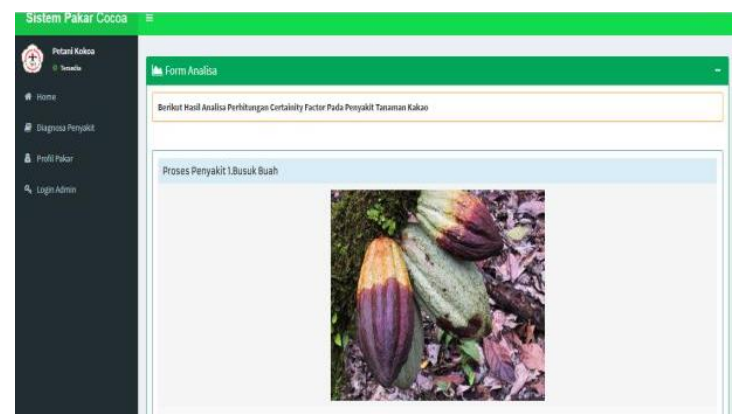

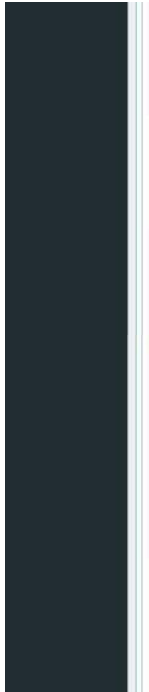

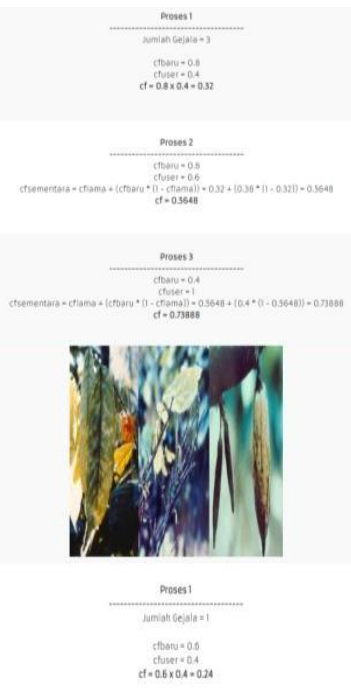

Gambar 9. Tampilan Menu Informasi Hasil

Diagnose

Tampilan menu informasi hasil diagnosa merupakan tampilan dari hasil diagnosa yang dilakukan oleh user. Pada tampilan ini sistem pakar penyakit tanaman kakao menampilkan hasil diagnosa berdasarkan setiap gejala dan tingkat keyakinan pertanyaan yang telah dijawab. Hasil yang akan ditampilkan yaitu berupa persentase kemungkinan penyakit yang dialami oleh tanaman kakao.
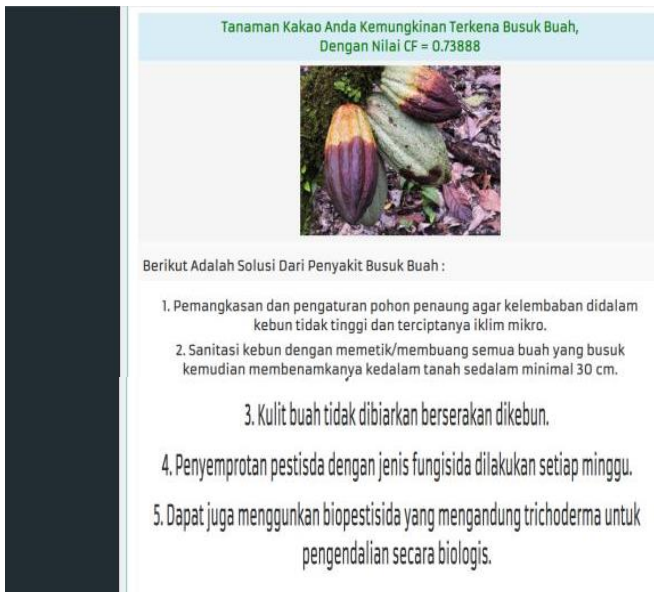

\section{Gambar 10. Tampilan Menu Informasi Hasil Diagnose}

\subsection{Uji Akurasi}

Uji akurasi dilakukan sebagai proses pengujian akurat sistem yang dibangun. akurasi sistem pakar berdasarkan 21 sampel tingkat akurasi sistem pakar diagnosis penyakit pada tanaman kakao menggunakan rumus perhitungan berikut.

$$
\begin{aligned}
\text { Akurasi } & =(\text { Hasil Tepat } / \text { Seluruh data }) * 100 \% \\
& =(18 / 21) * 100 \% \\
& =0,857 * 100 \%=85,7 \%
\end{aligned}
$$


Jadi dapat disimpulkan bahwa akurasi sistem pakar berdasarkan 21 data yang diuji adalah $85,7 \%$ yang menunjukan bahwa sistem pakar ini berfungsi dengan baik sesuai dengan diagnosa pakar. Ketidakakurasian sistem pakar ini 14,3 \% yang disebabkan karena beberapa kemungkinan antara lain pada saat kita hanya memilih 1 gejala saja yang dimiliki oleh 2 penyakit yang sama, maka sistem akan memilih dua penyakit dengan nilai probabilitas yang sama.

\subsection{Pengujian Blackbox Sistem Pakar}

Untuk Mendiagnosa Penyakit Tanaman Kakao Pengujian blackbox dilakukan sebagai proses pengujian kinerja atau tingkat keberhasilan sistem. Hal ini dilakukan dengan tujuan untuk mengetahui sejauh mana sistem memiliki tingkat keberhasilan pada pengujian blackbox. Berdasarkan pengujian yang dilakukan dengan ketepatan fungsi fungsi yang sesuai dengan kebutuhan sistem, sistem mendapatkan klasifikasi $84,62 \%$.

\section{Simpulan dan Saran}

\subsection{Simpulan}

Dari hasil selama perancangan, implementasi, dan proses uji coba perangkat lunak yang dilakukan, dapat ditarik kesimpulan:

1. Penerapan metode certainty factor untuk mengidentifikasi penyakit tanaman kakao dengan cara memasukan gejala penyakit tanaman kakao dan keyakinan kepercayaan yang dihitung dengan metode certainty factor.

2. Diagnosa sistem pakar menggunakan metode certainty factor telah sesuai dengan diagnosis seorang pakar, dibuktikan dengan hasil uji akurasi $85,7 \%$ keakuratan dari sistem dan $14,3 \%$ kesalahan sistem dalam mendiagnosa penyakit tanamn kakao.

\subsection{Saran}

Saran sehubungan dengan implementasi sistem pakar untuk mendiagnosa penyakit tanaman kakao ini adalah:

1. Diharapkan penelitian ini menjadi dasar untuk melakukan penelitian selanjutnya dan dapat menambahkan pembahasan tentang penyakit tanaman kakao lainnya.

2. Penelitian berikutnya dapat dilakukan dengan metode klasifikasi seperti Support Vector Machine (SVM) yang dikemukakan oleh [15] SVM menghasilkan akurasi lebih tinggi dibandingkan dengan metode klasifikasi yang lain.

3. Diharapkan aplikasi ini dapat dikembangkan lebih lengkap dengan menambahkan gambar pada setiap gejala agar dapat memudahkan pengguna dalam mendiagnosa penyakit yang terjadi pada tanaman kakao.

\section{References}

[1] L. Susanto, Kompendium Penyakit-penyakit Kakao, Yogyakarta: Lily Publisher, 2017.

[2] E. Turban, Expert Systems and Applied Artificial Intelligence, New Jersey, United States: Prentice Hall, 1992.

[3] D. Alita, S. Priyanta and N. Rokhman, "Analysis of Emoticon and Sarcasm Effect on Sentiment Analysis of Indonesian Language on Twitter," Journal of Information Systems Engineering and Business Intelligence, vol. 5, no. 2, pp. 100-109, 2019.

[4] L. Williams, Testing Overview and Black Box Testing Techniques, 2006.

[5] H. Sulistiani and K. Muladi, "Penerapan Metode Certainly Factor dalam Mendeteksi Penyakit Tanaman Karet," Jurnal Pendidikan Teknologi dan Kejuruan, vol. 15, no. 1, pp. 51-59, 2018.

[6] N. Kurniati, Y. Yanitasari, D. A. Lantana, I. S. Karina and E. R. Susanto, "Sistem Pakar untuk Mendiagnosa Penyakit Kulit pada Kucing Menggunakan Certainly Factor," Jurnal Ilmiah (ILKOM), vol. 9, no. 1, pp. 34-41, 2017.

[7] A. Nurkholis, A. Riyantomo and M. Rafrikan, "Sistem Pakar Penyakit Lambung Menggunakan Metode Forward Chainning," Majalah Ilmiah Momentum, vol. 13, no. 1, pp. 32-38, 2017.

[8] J. C. Giarratano, Expert Systems: Principles and Programming, Fourth Edition, Boston: Thomson Course Technology, 2005.

[9] E. Turban, Decision Support Systems and Intelligent Systems, Yogyakarta: Andi, 2005.

[10] W. Budiharti, Artificial Intelligence Konsep dan Penerapannya, Yogyakarta: Andi, 2014.

[11] G. Supriyanto, Jusak and P. Sudarmaningtyas, "Sistem Pakar Diagnosis Penyakit pada Tanaman Kelapa Sawit Menggunakan Metode Certainty Factor," Jurnal Sistem Informasi, vol. 3, no. 2, pp. 168-174, 2014.

[12] I. Sommerville, Software Engineering 9th Edition, Addison-Wesley, 2011.

[13] S. Rosa, Rekayasa Perangkat Lunak, Bandung: Informatika, 2014.

[14] E. Turban, Decision Support Systems and Intelligent System, Yogyakarta: Andi, 2005.

[15] Styawati, "A Support Vector Machine-Firefly Algorithm for Movie Opinion Data Classification," Indonesian Journal of Computing and Cyberetics Systems, vol. 3, no. 13, 2019. 